\title{
Research on Financial Early Warning of Listed Corporation Based on SOM Fusion BP Neural Network
}

\author{
Qun Meng \\ College of Economics Jinan University, Guangzhou, China \\ Email: mqueen@qq.com
}

Received 26 April 2016; accepted 24 May 2016; published 27 May 2016

Copyright (C) 2016 by author and Scientific Research Publishing Inc.

This work is licensed under the Creative Commons Attribution International License (CC BY). http://creativecommons.org/licenses/by/4.0/

(c) (i) Open Access

\begin{abstract}
Combining with the special environment of Chinese market, this paper defines the listed Corporation's financial crisis, and analyzes the shortcomings of the existing financial early warning model. In order to further improve the accuracy of the financial early warning, and adaptively select optimal training samples, short-term forecasting model of listed corporations based on the SOM network fusion BP network is proposed. The model firstly extracts the initial training samples relying on the SOM network and obtains the optimum ST samples and non ST samples in all training samples. Furthermore, the extracted samples are utilized to construct the financial early warning system of five different levels based on SOM network. Finally, the model is compared with other model algorithms. The results show that the financial early-warning model proposed in this paper possesses higher recognition accuracy on short term forecasting and monitoring of enterprise finance compared with other recognition models. Moreover, smaller data size is needed in this model on the premise that the effectiveness is guaranteed. Therefore, the early warning model proposed in this paper can better realize enterprise financial monitoring, so as to effectively prevent and defuse financial risks and crises.
\end{abstract}

\section{Keywords}

Financial Early Warning, SOM Network, BP Network, Short Term Forecast, Optimum Sample

\section{Introduction}

The world's listed companies in the global context of economic globalization will confront varieties of risks, among which economic crisis is closely associated with their survival and advancement [1] [2]. As China's financial system continues to reform and open up, the amount of listed companies have been growing in the se- 
curities market at home. Only two stock exchange markets of Shenzhen and Shanghai have 2781 A-share listed companies as of June 30 ${ }^{\text {th }}$, including 1719 A-share companies in Shenzhen Stock Exchange and 1062 in Shanghai Stock Exchange. The growingly fierce competition amongst more economic risks and companies can be shown in the phenomenon of a great number of listed companies. Thus, for each listed company, the early warning of financial crisis is an urgent issue that needs to be resolved.

Study on the warning of economic crisis has begun earlier in foreign nations in the study area of company's economic crisis. The economic early-warning models offer certain precaution and control of risk in overseas. However, because of differences in the market mechanisms, the models are mainly established on listing companies at home, which may not be applicable in Chinese market. Nonetheless, a relatively comprehensive economic early-warning system has not been built for listed companies in Chinese existing academic circle [3]-[5]. At the same time, the algorithm of model put forward in current literature have many disadvantages, for example, the inability to show the matching of modeling samples.

Thus, based on the summary of prior researched modeling algorithms and considering the particular environment of China's market, this article extracts the most important element of researches on economic early-warning and puts forward an economic early-warning system for listed companies on the basis of integrating BP and SOM neural network models and majorly emphasizing on short-run economic estimation and monitoring. First of all, the architectures of BP and SOM neural network models are introduced in this paper. Furthermore, computational procedures of algorithm for BP and SOM networks are analyzed. Relatively crucial samples are extracted adaptively through applying all the selected ST and non-ST samples into the SOM network. Subsequently, the relatively crucial samples are categorized into five grades of economic early-warning groups. Last but not least, with the usage of categorized five grades of samples, the economic early-warning and supervising system is established via BP network. Furthermore, the estimated accuracy of the modeling algorithm which has been put forward is studied by comparing other modeling algorithms.

\section{Definition of Economic Crisis for Listed Companies}

Recently, domestic and overseas researchers have different viewpoints regarding the definition of economic crisis [6]. In global scale, Altman as one of the early scholars considered that companies in economic crisis were those confronting with insolvency, business failure, legislative bankruptcy or breach of contract. According to Deakin, companies which were not able to meet the requirements of liquidation or liabilities for creditors' benefit were more likely to be in economic crisis. At the same time, delinquency and bankruptcy were defined by Beaver as the requirements to identify companies in economic crisis. Carmichael was not able to meet the requirement of liabilities as the economic crisis, which can be shown in the liquidity of capital, debt default and lack of equity. On the other side, company’s economic crisis was defined by Ross from four main aspects, including accounting bankruptcy, legal bankruptcy, business failure, and technical insolvency.

A great number of domestic scholars disagree that economic crisis should be determined by problems in companies or businesses. Instead, they consider profitability or integrated company losses as the requirements to define economic crisis. Amongst them, economic crisis was defined by Liu Shulian and Guqi as a financial phenomenon of company expenses. Also, economic crisis was identified via different types of costs. Guo Lihong and Chen Wenhao consider that in general, economic crisis means a financial phenomenon in which companies cannot pay back debts. Economic crisis was considered by Zhang Houqi et al. as an integrated process from establishing a company to its bankruptcy. The domestic and overseas definitions for company's economic crisis show that macroscopic features are usually considered as criteria of judgment aboard whereas economic crisis in Chinese market is mainly judged by whether a business is making money or losing it.

This paper studies domestic listed companies. Thus, economic crisis can be considered as below: because of stock abnormalities, under special treatment (ST) listed companies by stock exchanges. Specifically, ST companies refer to those in economic crisis while non-ST companies are those with healthy financial status. As this article emphasizes on the study of short-range early warning, only the selection of statistical samples in one year is needed. Therefore, non-ST and ST listed companies in 2014 are selected as sample companies for analysis.

\section{Creation of Economic Early-Warning Model for Listed Companies}

\subsection{SOM Neural Network-Oriented Adaptive Extraction of Samples}

As a kind of competitive neural network, self-organizing competitive neural network is also referred to as SOM 
neural network [7] [8]. Unsupervised learning is applied in the network, meaning that it is not necessary to give corresponding output. The unit connection weights are modified by the network via constant training based on specific criteria by simply depending on the inherent characteristics of input models. Also, the distribution of samples is similar to that of weight vector in the input vector space. According to Figure 1, fundamental competitive neural network is constituted of input and output layers. It is assumed that there are $M$ number of neurons in the competition layer and $N$ number of neurons in the input layer. The network connection weight is $w_{i j}$, its $(i=1,2, \cdots, N ; j=1,2, \cdots, M)$ which gratifies the constraint $\sum_{i=1}^{N} w_{i j}=1$. Neurons compete with each other in the competition layer and finally only one or a few could win to adjust to the existing input samples. The classifying pattern of existing input samples is represented by the winner neurons.

In the internal competition layer of above the SOM network, the neurons are competing with each other. At the same time, one neuron will win for the samples with similar attributes. The victorious neuron represents the category center of part input samples. In the model of competitive neural network, algorithmic flow is as below:

Step 1: According to the constraints, the random value in the interval $[0,1]$ is assigned to $w_{i j}$.

Step 2: A model $X$ from $T$ number of learning models is selected randomly and feed it to the network's output layer. Based on the Equation (1) as follow, the input value $S_{j}$ of every neuron in the competitive layer is calculated:

$$
S_{j}=\sum_{i=1}^{N} w_{i j} X_{i}
$$

in which $X_{i}$ is the $i$-th element of the input sample vector and $i=1,2, \cdots, N$.

Step 3: In correspondence to the maximal value amongst $S_{j}(j=1,2, \cdots, M)$, the neuron is considered as the winner and its output state is set to 1 , whereas the output statuses of all the other neurons are set to 0 . With the maximal weighting value, neural network $k$ in the competition layer finally wins according to the mechanism of competition,. Output $a_{k}$ is presented in Equation (2) as follow:

$$
a_{k}= \begin{cases}1, & s_{k}>s_{j}, \forall j, k \neq j \\ 0, & \text { Other }\end{cases}
$$

Step 4: Based on the below equation, every connection weight that is connected to the winner neuron is modified whereas maintaining weights connected to other unchanged neurons. Weight is presented in the Equation (3) as follow:

$$
w_{i j}=w_{i j}+a\left(\frac{X_{i}}{m}-w_{i j}\right)
$$

In which $a$ is the learning parameter, $0<a<1$, which is usually $0.01 \sim 0.03 ; i=1,2, \cdots, N$; $m$ is the amount of neurons with an output of 1 in the input layer.

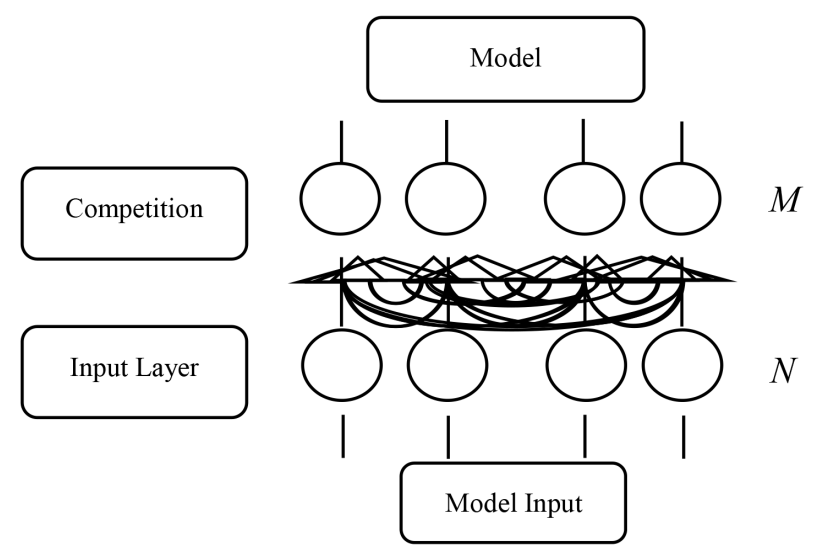

Figure 1. Architecture of SOM neural network model. 
Step 5: Another learning model is selected and returns to Step 3 till the $T$ number of learning model is fed to the network. Till the adjustment amount of every connection weight becomes small, return to Step 2.

\subsection{BP Neural Network-Based Recognition and Prediction}

The error back-propagation algorithm is utilized as the algorithm of learning by the BP neural network [9] [10]. As a feed-forward network, it is normally constituted of output layer, input layer and hidden layer. Neurons between the layers connect with each other via $w$, the corresponding network weight coefficient. In addition, in every layer, neurons are unconnected. BP algorithm has the basic idea that the forward-propagation of signals and back-propagation of errors are two procedures in the learning process. Figure 2 shows the specific architecture:

In which $j=1, \cdots, M$; $w_{i j}$ stands for the weight between $j$-th node of the input layer and $i$-th node of the hidden layer; $x_{j}$ stands for the input of $j$-th node of the input layer; $\phi(x)$ stands for the activation function of hidden layer; $\theta_{i}$ stands for the threshold of $i$-th node of the hidden layer; $i=1, \cdots, q ; a_{k}$ stands for the threshold of $k$-th node of the output layer, $k=1, \cdots, L$; $w_{k i}$ stands for the weight between $i$-th node of the hidden layer and $k$-th node of the output layer; $o_{k}$ stands for the output of $k$-th node of the output layer; $\psi(x)$ stands for the activation function of output layer.

Above BP network structure chart shows that, in a simple three-layer BP network, assume that the input vector is $X\left(x_{1}, x_{2}, \cdots, x_{n}\right)^{\mathrm{T}}$, output vector at the output layer is $O\left(o_{0}, o_{2}, \cdots, o_{n}\right)^{\mathrm{T}}$, output vector at the hidden layer is $Y\left(y_{1}, y_{2}, \cdots, y_{n}\right)^{\mathrm{T}}$, target output vector is $D=\left(D_{1}, D_{2}, \cdots, D_{n}\right)$, the connection weight from the input layer to the hidden layer is $V\left(v_{1}, v_{2}, \cdots, v_{n}\right)^{\mathrm{T}}$, and the connection weights from the hidden layer to the output layer is $W\left(w_{1}, w_{2}, \cdots, w_{n}\right)^{\mathrm{T}}$, the corresponding network iteration steps are as follows.

Step 1: Initialize the network weight matrix $W$ and $V$ in a random way. Set the corresponding learning rate as $\eta$, and the target error value as $E_{\min }$. At the same time, set the sample mode counter $p$ and the training frequency counter $q$ as 1 .

Step 2: Input training samples $\mathrm{D}$ and $\mathrm{X}$. Calculate the hidden layer output vector $\mathrm{Y}$ respectively, and the target output vector $O$. The calculation expressions are shown as Formula 4:

$$
\begin{aligned}
& o_{k}=f\left(\text { net }_{k}\right) \quad \text { net }_{k}=\sum_{j=0}^{m} w_{j k} y_{j} \\
& y_{j}=f\left(\text { net }_{j}\right) \quad \text { net }_{j}=\sum_{i=0}^{n} v_{i j} y_{j}
\end{aligned}
$$

where, $n e t_{j}$ and $n e t_{k}$ represent the transfer functions utilized in hidden layer and output layer.

Step 3: if there are totally $P$ pairs of training samples. Aiming at each different learning sample $p$, its network is corresponding to different error $E^{P}$, and its root-mean-square is utilized as the total error of the network. The calculation expressions are shown as Formula 5:

$$
E_{R M E}=\sqrt{\frac{1}{P} \sum_{p=1}^{P}\left(E_{P}\right)^{2}}
$$

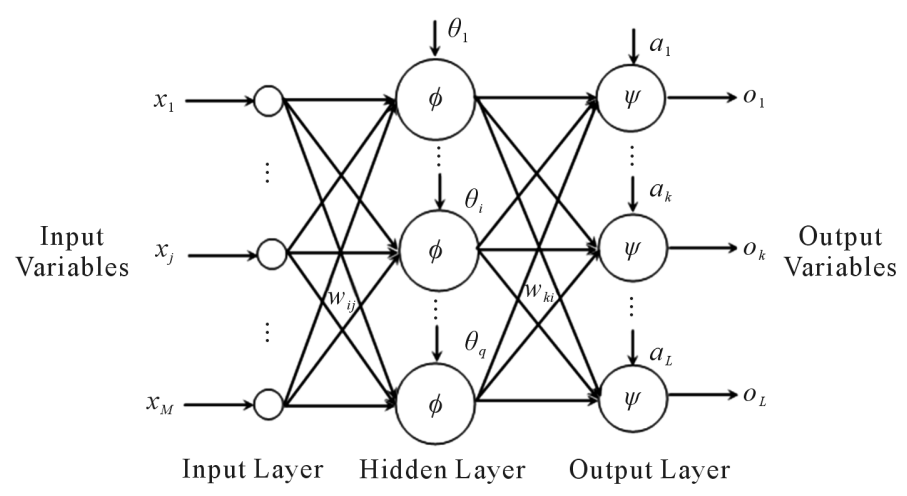

Figure 2. Architecture of BP neural network model. 
Step 4: calculate the error signal of each layer, where the calculation expressions are shown as Formula 6:

$$
\begin{aligned}
& \delta_{k}^{o}=\left(d_{k}-o_{k}\right)\left(1-o_{k}\right) o_{k} \\
& \delta_{j}^{y}=\left[\sum_{k=1}^{l}\left(d_{k}-o_{k}\right) f^{\prime}\left(\text { net }_{k}\right) w_{j k}\right] f^{\prime}\left(\text { net }_{j}\right)=\left(\sum_{k=1}^{l} \delta_{k}^{o} w_{j k}\right)\left(1-y_{j}\right) y_{j}
\end{aligned}
$$

Step 5: Adjust the weights of each network layer, where the calculation expressions are shown as Formula 7:

$$
\begin{aligned}
& \Delta w_{j k}=\eta \delta_{k}^{o} y_{j}=\eta\left(d_{k}-o_{k}\right)\left(1-o_{k}\right) o_{k} y_{j} \\
& \Delta v_{i j}=\eta \delta_{j}^{y} x_{i}=\left(\sum_{k=1}^{l} \delta_{k}^{o} w_{j k}\right)\left(1-y_{j}\right) y_{j} x_{i}
\end{aligned}
$$

Step 6: when the once trainings for all samples are completed, check whether the network training meets the termination conditions. If $E_{R M E}<E_{\min }$ or the training has achieved the maximum frequency, the algorithm is finished. Or else return to Step 2.

The information input iterative process of above mentioned BP neural network proves that this network possesses highly nonlinear characteristics. At the same time, the network iteration will be sent back reversely layer by layer by the error value. The weight of each layer is modified according to the specified learning rules to adjust weight coefficient reversely so that the network output is gradually approaching the actual value. Therefore, BP network can be applied to the prediction with highly nonlinear characteristics.

\subsection{Financial Early-Warning Model Based on SOM-BP Neural Network Models}

The features of BP and SOM as well as the neural network models as above show that when the early-warning model of the final model and the samples of input data contain non-ST and ST sample objects are categorized into two categories of object, the network of SOM can correct the unit connection weights by itself via the constant training based on the inherent characteristics of input models and enables the distribution of weight vector in the input vector space approximate the sample distribution. Therefore, the usage of SOM model enables the adaptive extraction of the non-ST and ST sample objects. The misclassified samples would be moved away at the end of the model training by returning the categories of all the sampling objects and comparing to the original sample kinds. Lastly, a system model with economic early-warning capability is established via the iterative training of BP neural network utilizing the samples which are screened as the training samples in the BP neural network. Samples are categorized into two kinds in the adaptive extraction process as above. The relatively optimal non-ST and ST samples which are extracted initially in practice could be distinguished in order to gain a multi-category early-warning system, win which the information of early-warning can be categorized in to different grades, including normal, alert, warning, severe warning and crisis.

Hence, the SVM-BP neural network-oriented economic early-warning model which is put forward here is established as below through the analysis of model algorithm as above.

Step 1: The economic index values of all non-ST and SR samples are calculated and normalized from 0 to 1.

Step 2: The relatively optimal non-ST and ST samples are initially screened out with the usage of the normalized economic index value of every sample object as the input information of SOM network. (The relatively major sample objects mean that when the non-ST and ST samples are subjected to simultaneous clustering discrimination for samples in the same categorization, ifthey are categorized correctly in the final results of discrimination, they will be relatively optimal samples, while the confused samples will be the misclassified samples.)

Step 3: The relatively optimal non-ST and ST sample data are classified and five grades of the input information in SOM network are categorized, including normal, alert, warning, serious warning and crisis.

Step 4: In order to establish a comprehensive system of economic early-warning model, the network with the five levels of early-warning samples is trained as the input information in the BP neural network.

\section{Model Application and Result Analysis}

\subsection{Selection and Calculation of Sample Indices}

The selected economic indices should completely show the companies’ profitability, solvency, cash flow, oper- 
ating ability and other economic conditions in order to objectively and fully describe the economic positions of listed companies. The actual conditions of China are considered and the availability of economic data, 16 economic indices in total are chosen as the theoretical system of economic crisis early-warning by referencing the related literature [11]. Table 1 shows the financial indices of listed companies utilized in this research and related computational formulas. All the selected data are the economic data in 2014, including 44 ST samples and 68 non-ST samples. Table 2 shows some index values of the sample data.

\subsection{Solution of Economic Early-Warning Model}

\subsubsection{Initial Extraction of All Samples}

The economic index data of every sample which is selected can be utilized as the network inputs of SOM. Figure 3 shows the architectural diagram in the competitive neural network.

Table 3 shows the parameters during network training. Trainru function (unsupervised random) is applied in network training. The maximal number of iterations is 50 whereas both of adjusted learning rate and initial learning rate are 0.3 .

The initial discrimination kinds of SOM model are 2 as the extraction of relatively optimal non-ST and ST samples in the sample objects is first required. Figure 4 shows the discrimination results of the obtained sample objects.

The number of non-ST samples in total is 68. The discrimination results of non-ST sample as above show that 40 samples are discriminated accurately, whereas 28 samples are discriminated accurately. Specifically, 28 samples are excluded whereas 40 relatively optimal samples are extracted. In similar way, the number of ST company samples is 44 in total, 2 of which are discriminated erroneously. Specifically, 42 relatively optimal samples can be extracted. Therefore, based on initial extraction, the number of relatively optimal samples is 82 in total.

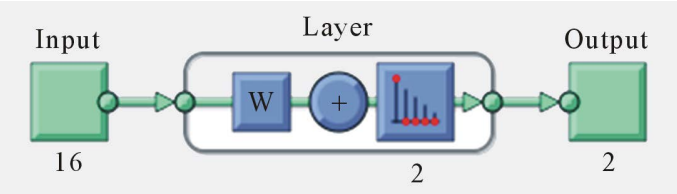

Figure 3. Architectural diagram of the neural network model of SOM.

Table 1. Financial crisis early-warning indices for listed companies.

\begin{tabular}{|c|c|c|c|}
\hline Group & No. & Financial index & Computational formula \\
\hline \multirow{4}{*}{ Cash flow } & $\mathrm{X} 1$ & Net operating cash flow-to-sales ratio & Net cash flow from operating activities/operating income \\
\hline & $\mathrm{X} 2$ & Operating cash flow of assets & Net cash flow from operating activities/total assets \\
\hline & $\mathrm{X} 3$ & Cash flow ratio & Net cash flow from operating activities/total current liabilities \\
\hline & $\mathrm{X} 4$ & Net operating cash flow per share & Net cash flow from operating activities/total equity \\
\hline \multirow{3}{*}{ Operating capacity } & $\mathrm{X} 5$ & Accounts receivable turnover & Operating income/accounts receivable \\
\hline & $\mathrm{X} 6$ & Total assets turnover & Operating income/total assets \\
\hline & $\mathrm{X} 7$ & Net assets per share & Stockholders’ equity/total equity \\
\hline \multirow{4}{*}{ Profitability } & X8 & Return on equity & Net profit/stockholders' equity \\
\hline & X9 & Rate of return on total assets & Net profit/operating profit \\
\hline & $\mathrm{X} 10$ & Rate of return on operating income & Net profit/(operating income + non-operating income) \\
\hline & $\mathrm{X} 11$ & Earnings per share & Net profit/total equity \\
\hline \multirow{5}{*}{ Solvency } & $\mathrm{X} 12$ & Current ratio & (Total current assets - inventories)/total current liabilities \\
\hline & $\mathrm{X} 13$ & Quick ratio & Total current assets/total current liabilities \\
\hline & $\mathrm{X} 14$ & Stockholders' equity ratio & Stockholders’ equity/total assets \\
\hline & X15 & Asset-liability ratio & Total liabilities/total assets \\
\hline & $\mathrm{X} 16$ & Cash ratio & Ending cash/total current liabilities \\
\hline
\end{tabular}


Table 2. Financial index value of part ST and non ST companies in 2014.

\begin{tabular}{|c|c|c|c|c|c|c|}
\hline \multirow{2}{*}{ Company name } & \multicolumn{3}{|c|}{ Non ST } & \multicolumn{3}{|c|}{ ST } \\
\hline & $\begin{array}{c}\text { Island } \\
\text { Construction }\end{array}$ & Baihuacun & Tianying & $\begin{array}{l}\text { Pyrus bretschneideri } \\
\text { Rehd }\end{array}$ & Zhongyida & Jinniu Chemical \\
\hline stock code & C600515 & C600721 & C000035 & C600506 & C600610 & C600722 \\
\hline $\mathrm{X} 1$ & 0.28040 & 0.53135 & 0.66110 & -0.00988 & -0.68549 & -0.02937 \\
\hline $\mathrm{X} 2$ & 0.08457 & 0.02297 & 0.06550 & -0.00223 & -0.03371 & -0.00807 \\
\hline $\mathrm{X} 3$ & 0.26700 & 0.04492 & 0.44601 & -0.02299 & -0.04612 & -0.01899 \\
\hline $\mathrm{X} 4$ & 0.73992 & 0.37521 & 0.30458 & -0.00488 & -0.03203 & -0.03670 \\
\hline X5 & 24.13638 & 1.77679 & 2.14217 & 101.28126 & 5.76575 & 33.20933 \\
\hline $\mathrm{X} 6$ & 0.30162 & 0.04323 & 0.09907 & 0.22601 & 0.04917 & 0.27470 \\
\hline $\mathrm{X} 7$ & 1.93620 & 3.61000 & 2.50960 & 1.89000 & 0.23000 & 1.19980 \\
\hline $\mathrm{X} 8$ & 0.04565 & -0.01221 & 0.06390 & -0.02702 & -0.06243 & -0.12123 \\
\hline X9 & 0.71496 & 1.24002 & 0.94798 & 0.97427 & 0.53520 & 1.03749 \\
\hline $\mathrm{X} 10$ & 0.03347 & -0.06209 & 0.34063 & -0.10337 & -0.24286 & -0.11622 \\
\hline $\mathrm{X} 11$ & 0.09000 & -0.04000 & 0.26000 & -0.05000 & -0.01000 & -0.16000 \\
\hline $\mathrm{X} 12$ & 1.11085 & 0.25061 & 2.45464 & 0.64715 & 0.43955 & 0.43912 \\
\hline $\mathrm{X} 13$ & 1.12151 & 0.40156 & 2.65247 & 3.22069 & 0.52032 & 0.56216 \\
\hline $\mathrm{X} 14$ & 0.22131 & 0.22104 & 0.53966 & 0.86583 & 0.24294 & 0.26370 \\
\hline X15 & 0.77869 & 0.69383 & 0.46034 & 0.13058 & 0.75682 & 0.66868 \\
\hline X16 & 1.02288 & 0.06748 & 1.32421 & 0.28109 & 0.05649 & 0.19188 \\
\hline
\end{tabular}

Table 3. Parameters during the training of SOM neural network.

\begin{tabular}{ccc} 
Layout function & Hex top function & Leaming rate in adjustment phase \\
Distance function & Link dist function & Adjacent distance in adjustment phase \\
Leaming rate in sorting & 0.3 & Number of network iterations \\
Phase & 200 & Network training function \\
Step size in sorting phase & 200 & Trainru function \\
\hline
\end{tabular}

\subsubsection{Grade Early-Warning Categorization of Relatively Optimal Samples}

The initially extracted samples as above are utilized as the input information in the SOM network again. The discrimination kinds of SOM model are 5 since the final model categorizes the company's early-warning into five levels, including normal, alert, warning, severe warning and crisis. Figure 5 shows the categorization results of different samples.

In the process of classification, the latter 42 sample data are ST companies while the previous 40 sample data are non-ST companies. Figure 5 shows that for non-ST companies, the results of economic include three categorizes which are normal, alert and warning. On the other hand, as for ST companies, all the results of economic early-warning are severe crisis and warning. Therefore, a sound gradient is shown in the early-warning grading as above. 

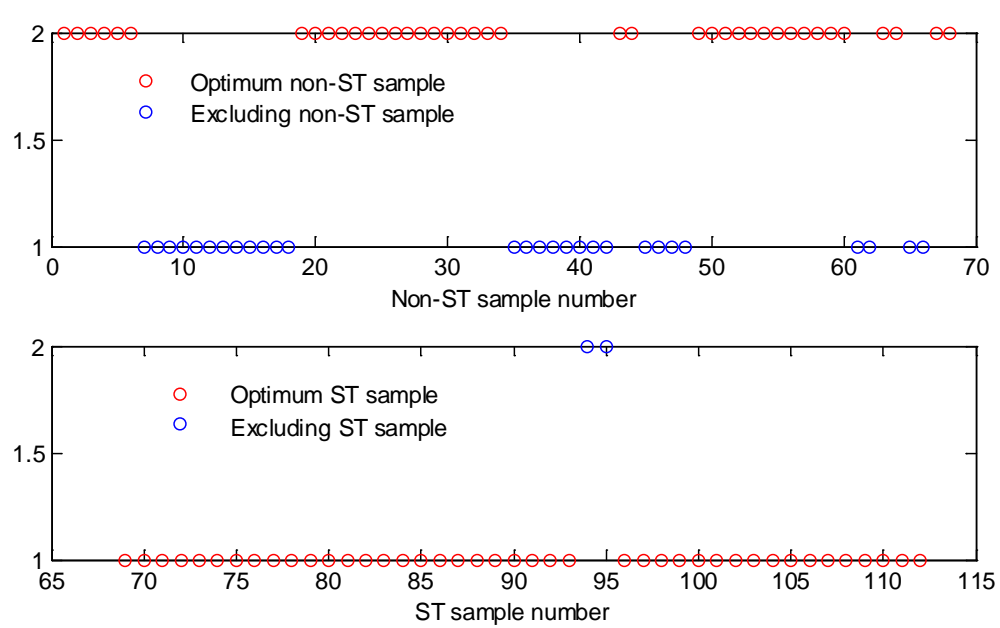

Figure 4. The results of the sample extraction of the listed corporation.

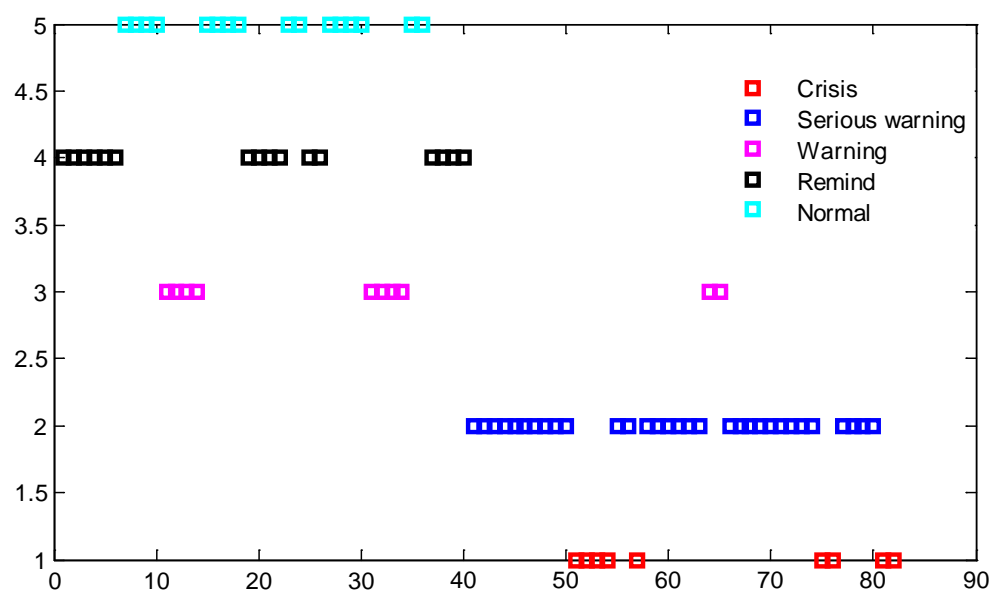

Figure 5. 5-grade early-warning categorization results of samples.

\subsection{Construction of Economic Early-Warning System}

The categorized grades of samples as above are utilized as the network inputs of SOM. During the convergence and training of BP neural network, parameters are presented in Table 4 below. Figure 6 shows the dynamic transformations in errors during the process of network training.

Aiming at various output targets in the process of network training, the encoding forms in following Table 4 is utilized. Through the training of BP neural network, the error dynamic change of the network training process is shown as Figure 6.

Through above BP network training, during the network convergence, there are a total of 340 times of iterations, and the error value of network convergence is $9.987 \times 10^{-6}$. Its overall goodness of fit has reached 0.99999. Finally, above mentioned training network is conducted with forecasting tests, during which Table 5 gives the forecasting results of original data directly utilizing Logistic model, BP neural network model and SVM model algorithm so as to compare the effectiveness of BP neural network model based on SOM fusion.

Table 6 shows that the model algorithm put forward here is of high accuracy of recognition for short-run economic warning. The major reason is that the model of SOM automatically matches the number of non-ST and ST company samples and excludes poor training samples in the process of sample data extraction. In the meantime, for short-run forecasting, the model is of high validity when the amount of data is small as the relatively optimal samples are extracted in the proposed algorithm. On the contrary, other models show forecasting capabilities and affected training since a great number of confused samples are included in the training sample objects, which therefore decreases their accuracy of forecast. 
Table 4. Crucial parameters of network convergence results and network training settings.

\begin{tabular}{ccccc}
\hline Network training parameters & Settings & Network training parameters & Settings \\
\hline Network layers & 2 & Network training function & Train lm \\
Number of nodes in the first layer & 20 & The first layer transfer function & $\log$ sig \\
Number of nodes in the second layer & 5 & The second layer transfer function & tan sig \\
Network target error & 0.00001 & Learning rate & 0.3 \\
\hline
\end{tabular}

Table 5. Output target codes of various financial early warning.

\begin{tabular}{cccccc}
\hline & Crisis & Serious warning & Warning & Remind & Normal \\
\hline \multirow{3}{*}{ Coding form } & 1 & 0 & 0 & 0 & 0 \\
& 0 & 1 & 0 & 0 & 0 \\
& 0 & 0 & 1 & 0 & 0 \\
\hline
\end{tabular}

Table 6. Comparison of early-warning recognition accuracy between models.

\begin{tabular}{ccc}
\hline Model algorithm & Accuracy & Error rate \\
\hline Logistic model & $81.3 \%$ & $18.7 \%$ \\
BP neural network model & $74.5 \%$ & $25.5 \%$ \\
SVM model & $88.2 \%$ & $11.8 \%$ \\
Present model & $94.7 \%$ & $5.3 \%$ \\
\hline
\end{tabular}

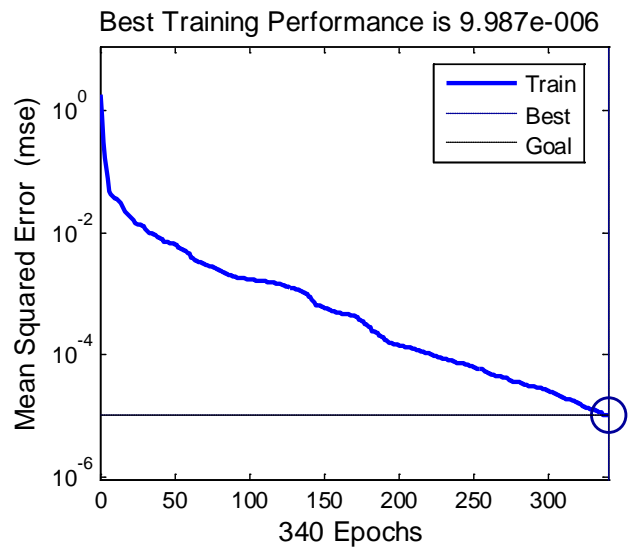

(a)

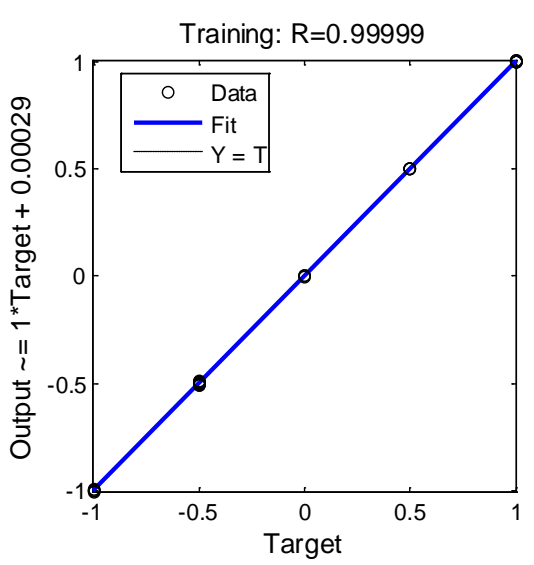

(b)

Figure 6. BP network training results; (a) error dynamic change results in network training process; (b) Global fitting and optimal results for network convergence.

\section{Conclusion}

On the basis of the detailed definition of the economic crisis, this paper establishes the economic early warning model of stock listed company. Financial Early Warning proposed model with forecasting function, compared with other recognition model, financial early warning model presented in this paper has higher recognition accuracy. The maximum contribution of the article is that warning proposed model can better achieve corporate 
financial supervision, so as to effectively prevent and resolve financial risks and crises. The limitation of the paper is lack of the latest research data, which may affect the results of the study.

\section{References}

[1] Eichengreen, B. and Gupta, P. (2013) The Financial Crisis and Indian Banks: Survival of the Fittest? Journal of International Money \& Finance, 39, 138-152. http://dx.doi.org/10.1016/j.jimonfin.2013.06.022

[2] James, B.W., Park, D., Jha, S., et al. (2008) The US Financial Crisis, Global Financial Turmoil, and Developing Asia: Is the Era of High Growth at an End? Asian Development Bank Economics Working. Paper Series No. 139. https://www.researchgate.net/publication/259978701_The_US_Financial_Crisis_Global_Financial_Turmoil_and_Deve loping_Asia_Is_the_Era_of_High_Growth_at_an_End

[3] Gang, R., Bose, I., Chen, X., et al. (2015) Prediction of Financial Distress: An Empirical Study of Listed Chinese Companies Using Data Mining. European Journal of Operational Research, 241, 236-247. http://dx.doi.org/10.1016/j.ejor.2014.08.016

[4] Li, B.A. (2015) Research on the Early Warning System of Financial Distress of Chinese Property Insurance Companies. Journal of Insurance Professional College, 29, 5-8.

[5] He, Y.M., Li, M. and Xu, X.Y. (2014) Information Processing in Design and Testing of Financial Early Warning Method of Listed Companies in China-Based on the Logistic Regression Analysis. Advanced Materials Research, 1022, 325-328. http://dx.doi.org/10.4028/www.scientific.net/AMR.1022.325

[6] Fabbrini, V., Guidolin, M. and Pedio, M. (2016) The Background: Channels of Contagion in the US Financial Crisis. Transmission Channels of Financial Shocks to Stock, Bond, and Asset-Backed Markets: An Empirical Model. Palgrave Macmillan, London.

[7] Hu, Q.H., Wang, C., Zhang, X., et al. (2015) Application of SOM Neural Network in Litho logy Recognition. Applied Mechanics \& Materials, 713-715, 2169-2172. http://dx.doi.org/10.4028/www.scientific.net/AMM.713-715.2169

[8] Zhao, J.H. and Computer, C.O. (2015) Semi-supervised Classification Algorithm Based on SOM Neural Network. Journal of Xihua University, 34, 36-40.

[9] He, W. (2013) An Inventory Controlled Supply Chain Model Based on Improved BP Neural Network. Discrete Dynamics in Nature \& Society, 2013, 1-7. http://dx.doi.org/10.1155/2013/537675

[10] Pratimsarangi, P., Sahu, A. and Panda, M. (2013) A Hybrid Differential Evolution and Back-Propagation Algorithm for Feedforward Neural Network Training. International Journal of Computer Applications, 84, 1-9.

[11] Zhuang, Y. and Zhu, X.J. (2013) On the Construction of the Financial Early-Warning Model—Based on Empirical Data Collected from China's Securities Market. Journal of Guangxi University of Finance \& Economics, 2013-04. http://en.cnki.com.cn/Article_en/CJFDTOTAL-GXSY201304018.htm 